\title{
Knowledge, Attitude and Practice of Contraception among Postpartum Women Attending Kathmandu Medical College Teaching Hospital
}

\section{Bajracharya A}

\author{
Department of Obstetrics and Gynecology \\ Kathmandu Medical College Teaching Hospital, \\ Kathmandu, Nepal
}

\section{Corresponding Author}

Anu Bajracharya

Department of Obstetrics and Gynecology

Kathmandu Medical College Teaching Hospital,

Kathmandu, Nepal

E-mail: dr.anubajracharya42@gmail.com

\section{Citation}

Bajracharya A. Knowledge, Attitude and Practice of Contraception among Postpartum Women Attending Kathmandu Medical College Teaching Hospital. Kathmandu Univ Med J 2015;52(4):292-7.

\section{ABSTRACT}

\section{Background}

Failure to plan a pregnancy can adversely affect the health of the family as a whole. High parity is related to increased maternal, perinatal and infant deaths and is associated with nutritional problems of both mother and child. Hence, good knowledge, attitude and practice of family planning among women are important. This study is aimed to determine the knowledge, attitude and practice of contraception among the postpartum women attending Kathmandu Medical College Teaching Hospital.

\section{Objective}

To determine the knowledge, attitude and the practice of various contraceptive methods among the postpartum women.

\section{Method}

A cross-sectional observational study was conducted in the department of Obstetrics and Gynecology on 400 postpartum women (within 42 days of delivery) who delivered and came for follow-up in this institution. All the postnatal women were interviewed with pre-designed questionnaire and information on sociodemographic variable, awareness and knowledge of various contraceptive methods, previous and current use of family planning methods, source of information, utilization and reasons for use/non-use of family planning methods were obtained. Data collected were entered and analyzed using SPSS 20 . The results were presented as percentages, means, tables and charts.

\section{Result}

Majority of the participants 363 (90.8\%) were aware of contraceptive usage. Amongst $60.5 \%$ of women who had previously used contraception, OCPs were the commonest one. Maximum number of participants $(60.35 \%)$ had used modern contraceptives in the past. The most common source of information on contraception was media (55.7\%). The reason of using contraception was spacing between the subsequent pregnancies, while the most common reason of discontinuation or not willing to use family planning methods was husband being abroad, fear of side effects and not knowing which contraceptives to use.

\section{Conclusion}

The contraceptive awareness and knowledge among the postpartum women was high but their usage was low. Hence, efforts should be made to educate the public about safety and convenience of modern methods of contraceptives. Health care personnels should also counsel the clients for adopting the contraceptives according to their need.

\section{KEY WORDS}

Contraception, knowledge, postpartum, practice 


\section{INTRODUCTION}

Globally, an estimated 300,000 maternal deaths occur annually owing to causes associated with pregnancy, of which nearly $75 \%$ were preventable. ${ }^{1}$ In developing countries, 55 million unintended pregnancies occur every year to women not using contraceptive method; another 25 million occur as a result of incorrect or inconsistent use of contraceptive method and method failure. ${ }^{2}$ Failure to plan a pregnancy can adversely affect the health of the family as a whole and the health of mothers and children remain a subject of global concern. ${ }^{3,4}$

Different research had established that many postpartum women have an unmet need for contraception, and that much of unmet need falls within the general postpartum period. $^{5}$ In Nepal, the concept of family planning was introduced by the Family Planning Association of Nepal (FPAN), set up by a group of social workers in 1959, since then many strategies and planning have taken place and thus there was the development of National Family Planning Strategy in 2012 by Ministry of Health and Population, Family Health Division to further strengthen and address the existing gaps of family planning program in Nepal. ${ }^{6}$ However, Nepal Demographic Health Survey (NDHS) 2011 has shown unexpected results on contraceptive prevalence rate (CPR). Although CPR of all methods increased from $48 \%$ in 2006 to $50 \%$ in 2011, there was a slight decrease in CPR of modern methods from $44.2 \%$ to $43.2 \%$ during the same period. ${ }^{7}$

In the effort to reduce maternal deaths in developing nations, family planning can be an important and effective step. Keeping this in mind, this cross sectional study was carried out to assess the level of knowledge/awareness about different types of family planning (FP) methods, attitude towards contraceptives and also to find out the practices of contraceptives among the postpartum women who had delivered in Kathmandu Medical College Teaching Hospital (KMCTH). All the post partum women were enrolled for the study because it offers the best environment within the hospital and best time period to discuss about the different family planning methods, correction of wrong perceptions about the contraceptives and use of correct contraceptive methods according to the need.

\section{METHODS}

This cross-sectional and descriptive hospital based study was carried out in the department of Obstetrics and Gynecology in Kathmandu Medical College Teaching Hospital (KMCTH). The study was carried out after obtaining the approval from the Ethical and Research Committee of $\mathrm{KMCTH}$ and after taking consent from the patients who were willing to participate. Non-cooperative women who refused to furnish necessary information were excluded.

The sample size was determined by using the Kish's formula $\left(\mathrm{N}=\mathrm{Z}^{2} \mathrm{PQ} / \mathrm{D}^{2}\right)$ and calculating the current contraceptive prevalence rate in Nepal according to Nepal Demographic Health Survey (NDHS) to be $50 \% .^{7}$ The duration of the study was two months from $1^{\text {st }}$ October 2014 to $30^{\text {th }}$ November 2014. The study population comprised of 400 postpartum women (taken both normal and cesarean deliveries within 42 days of postpartum period) who delivered in KMCTH and who came for follow up in the Gynecology outpatient department (GOPD) for child vaccination or for family planning counseling. They were interviewed with pre-designed questionnaire and information on sociodemographic variable, awareness and knowledge of various contraceptive methods (ocp, depot provera, IUCD, implants, condom, emergency contraceptives, vaginal foams or suppositories, female sterilization, male sterilization, breast feeding and traditional methods), previous and future use of family planning methods, source of information, utilization and reasons for use/nonuse of family planning methods were obtained. Privacy and confidentiality, respect of respondent's rights were strictly considered and consent taken during data collection. Data collected were entered in Microsoft Excel 2007 and then analyzed by using SPSS 20 on personal computer and subjected to descriptive analysis. The results were presented in percentages, means, tables and charts.

\section{RESULTS}

A total of 400 postpartum women were included in the study. Sociodemographic characteristics of the participants along with their knowledge and practice of family planning methods are summarized in Table 1 . The age range of the participant's was 18 to 40 years with mean age of 25.83 years. Majority of the women $(90.25 \%)$ were in the age group 20-34 years and majority of them were housewives (71.80\%). Total $56.80 \%$ were primipara whereas $43.30 \%$ were multipara and the parity range was 1-4 with a mean parity of 1.4 . Similarly, $68.30 \%$ were from urban area and $31.80 \%$ came from rural region. Upper caste $(61.25 \%)$ constituted the major ethnic group and majority (37.80\%) of the participant's educational level was above SLC. The study showed that more than 35 years were $100 \%$ aware of the family planning methods and adolescent had less knowledge (Table 1); urban women had slightly higher awareness than rural women. Laborers and housewives were less aware than women with other occupations. Upper caste group and relatively advantaged janajatis were more aware of the family planning methods in comparison with other ethnic groups. As education of the women increased to secondary and higher level, level of awareness also increased. 
Table 1. Socio-demographic characteristics of the study population with family planning knowledge and practice $(N=400)$

\begin{tabular}{|c|c|c|c|c|}
\hline Characteristics & $\mathbf{n}$ & $\%$ & $\begin{array}{l}\text { FP knowledge } \\
\text { no. (\%) }\end{array}$ & $\begin{array}{l}\text { FP used in the } \\
\text { past no. (\%) }\end{array}$ \\
\hline \multicolumn{5}{|l|}{ *Age (years) } \\
\hline$<19$ & 21 & 5.25 & $12 \quad(57.10)$ & $3 \quad(14.3)$ \\
\hline $20-34$ & 361 & 90.25 & $327(90.60)$ & $140(38.7)$ \\
\hline $35-40$ & 18 & 4.50 & $18 \quad(100)$ & $8 \quad(44.4)$ \\
\hline \multicolumn{5}{|c|}{ Mean: 25.83 yrs. (Range: $18-40$ yrs.) } \\
\hline \multicolumn{5}{|l|}{$* *$ Area of residence } \\
\hline Urban & 273 & 68.30 & 252 (92.30) & $103(37.9)$ \\
\hline Rural & 127 & 31.80 & $105(82.70)$ & $46 \quad(36.2)$ \\
\hline \multicolumn{5}{|l|}{ Occupation } \\
\hline Housewife & 287 & 71.80 & $247(86.10)$ & $106(37)$ \\
\hline Laborer & 7 & 1.8 & $6 \quad(85.70)$ & $3 \quad(42.90)$ \\
\hline Service & 66 & 16.50 & $64(97)$ & $25(37.90)$ \\
\hline Business & 24 & 6 & $24(100)$ & $11(45.80)$ \\
\hline Others & 16 & 4 & $16(100)$ & $5 \quad(31.30)$ \\
\hline \multicolumn{5}{|l|}{$* * *$ Ethnicity } \\
\hline Upper caste group & 245 & 61.25 & $231(94.30)$ & $86 \quad(35.20)$ \\
\hline $\begin{array}{l}\text { Relatively advan- } \\
\text { taged janajatis }\end{array}$ & 65 & 16.25 & $60 \quad(92.10)$ & $43.3(28)$ \\
\hline Religious minorities & 10 & 2.50 & $4 \quad(41.70)$ & $2 \quad(25)$ \\
\hline $\begin{array}{l}\text { Disadvantaged non- } \\
\text { dalit terai }\end{array}$ & 14 & 3.50 & $12(85.70)$ & $6 \quad(42.90)$ \\
\hline $\begin{array}{l}\text { Disadvantaged } \\
\text { janajatis }\end{array}$ & 66 & 16.50 & $50(76.60)$ & $28 \quad(41.90)$ \\
\hline Dalit & - & - & - & - \\
\hline \multicolumn{5}{|l|}{ Education } \\
\hline Illiterate & 28 & 7 & $18(64.20)$ & $15(53)$ \\
\hline Below SLC & 112 & 28 & $96 \quad(85.70)$ & $73(65.10)$ \\
\hline $\begin{array}{l}\text { Above SLC } \\
\text { (higher secondary) }\end{array}$ & 151 & 37.80 & $141(93.30)$ & 93 (61.58) \\
\hline $\begin{array}{l}\text { University } \\
\text { (Masters level) }\end{array}$ & 109 & 109 & $108(99.08)$ & $48(44.03)$ \\
\hline \multicolumn{5}{|c|}{$\begin{array}{l}\text { * Age is categorized according women's fertility and biological clock. } \\
\text { ** Area of residence: Rural (within VDC), urban (within municipality). } \\
\text { *** Ethnicity categorized as per Central Bureau Statistic of Nepal (Caste, } \\
\text { Ethnic \& Regional Identity in Nepal, 2006) }\end{array}$} \\
\hline
\end{tabular}

\section{Knowledge and source of information of different types of contraceptive methods}

Among different contraceptive methods (OCP, depot provera, condom, implants, IUCD, foams or vaginal, emergency contraceptives, female sterilization, male sterilization, breastfeeding and traditional methods) $90.80 \%$ of the participants were aware about at least one method. The most widely known contraceptives were condom (84\%), oral contraceptive pills (82\%) and injectables depot provera (71.50\%) respectively (Fig. 1). Family planning information was obtained from media (55.70\%), followed by health workers $(25.30 \%)$, friends/ relatives (13.50\%) largely accounted for the sources of awareness of contraception (Fig. 2).

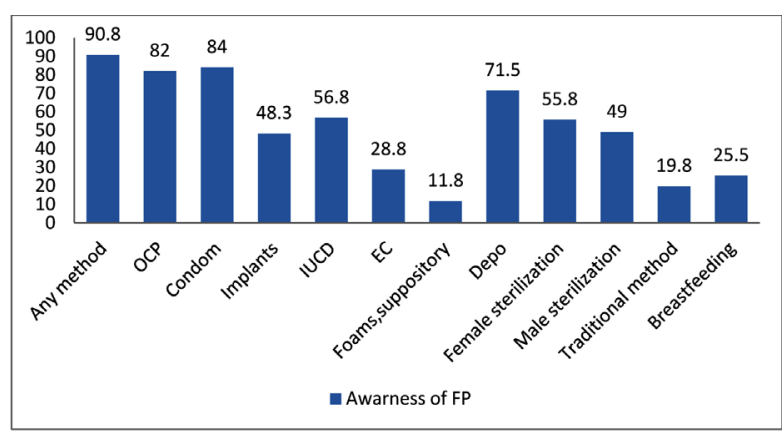

Figure 1. Knowledge of different types of family planning methods

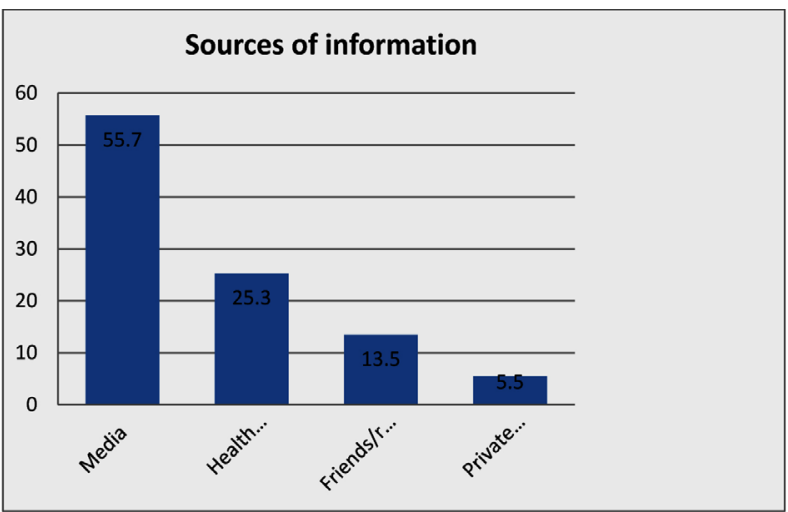

Figure 2. Media (TV, radio, newspapers), health workers (doctors, sisters), other sources (friends, neighbors, relatives), private sectors (NGOs)

\section{Attitude towards contraception}

Total 274 (68.50\%) women had positive attitude towards family planning and were ready to use it when needed or if appropriate methods available, while 90 (22.50\%) women did not want to use any family planning methods and 36 (9\%) women did not show any response or were unsure of using contraceptives (Fig. 3). The reasons for using and not using contraceptives are shown in (Table 2 and 3 ).

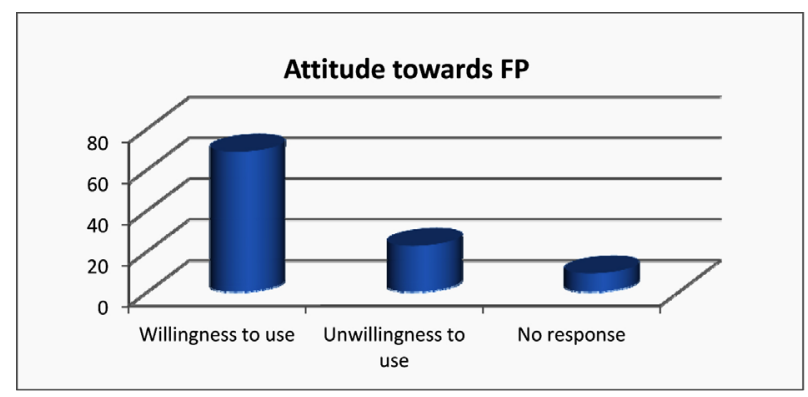

Figure 3. Attitude of women towards family planning methods

\section{Practice of contraception}

A total of 242 (60.50\%) of the participants had used one form or the other methods of contraception in the past, while 158 (39.50\%) had not used any methods. Among the total participants 241 (60.35\%) participants had used modern temporary contraceptive methods at least once, pills being the commonest $(23.80 \%)$ followed by depot 
Table 2. Willingness to use FP:

\begin{tabular}{|lll|}
\hline Reason to use & $\mathbf{n = 2 7 4}$ & $\%$ \\
\hline Spacing between child & 133 & 33.2 \\
\hline Husband's advise & 35 & 8.8 \\
\hline Health reason & 41 & 10.2 \\
\hline Financial difficulty & 15 & 3.8 \\
\hline Doctor's advise & 43 & 10.7 \\
\hline Complete family & 7 & 1.8 \\
\hline
\end{tabular}

Table 3. Unwillingness/unsure to use FP:

\begin{tabular}{|lll|}
\hline Reason for not to use & $\mathbf{n = 1 2 6}$ & $\%$ \\
\hline No specific reason & 64 & 16 \\
\hline Husband abroad & 29 & 7.3 \\
\hline Worried about side effects & 16 & 4 \\
\hline Opposition from family & 4 & 1 \\
\hline Wanted to have child & 6 & 1.5 \\
\hline Could not access FP & 5 & 1.2 \\
\hline Wants to have male child & 2 & 0.5 \\
\hline
\end{tabular}

provera (13.30\%). About $68.50 \%$ of the participants wanted to use contraceptives in the future and the most preferred method for future use being depot provera (23\%) shown in fig. 4.

\section{Relation of Level of education with future use of contraceptives:}

In this study, among 109 women doing their masters level, $92(84.40 \%)$ were willing to use contraceptives whereas among 28 illiterate women, 10(35.70\%) women would like to use contraceptives in future.

It is seen from fig. 5 that as education level increases i.e. above SLC level, women wanted to use family planning methods to limit their pregnancies.

\section{DISCUSSION}

Contraception is an important aspect of reproductive health and plays a major role in the prevention of unwanted pregnancy. In the present study, majority of women $(90.8 \%)$ had knowledge of at least one or other method of contraception. Similar to this study, SK Kausal and Shweta et al. found more than $90 \%$ awareness of family planning methods. ${ }^{8,9}$ Though there is high level $(90.80 \%)$ of awareness of contraceptives in this study, there is less usage i.e. only (60.50\%). The main reason behind this is more than half of the participants had no knowledge regarding the types of contraceptives they should use according to their need. Another reason of not using contraceptives is fear of its side effects and most of the participant's husband being abroad. This high level of contraceptive awareness and low level of usage has also been previously established. ${ }^{10}$

Among the various family planning methods, knowledge of participants on family planning methods in our study

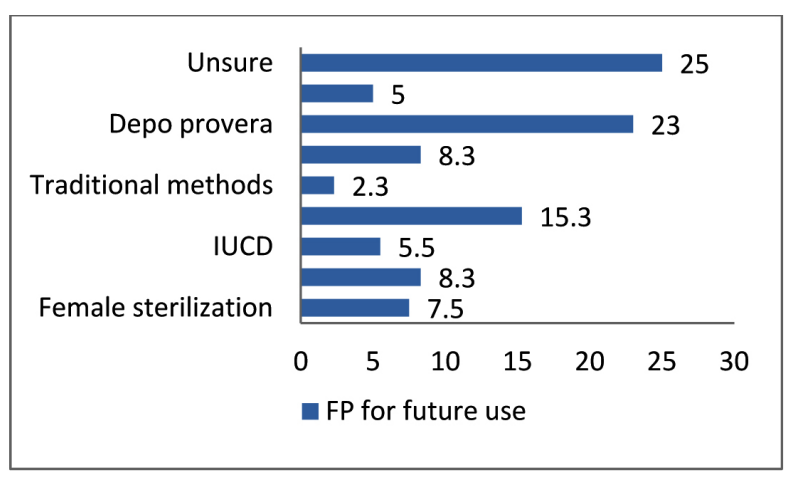

Figure 4. Percentage of Family planning devices preferred for future use $(\mathrm{N}=400)$

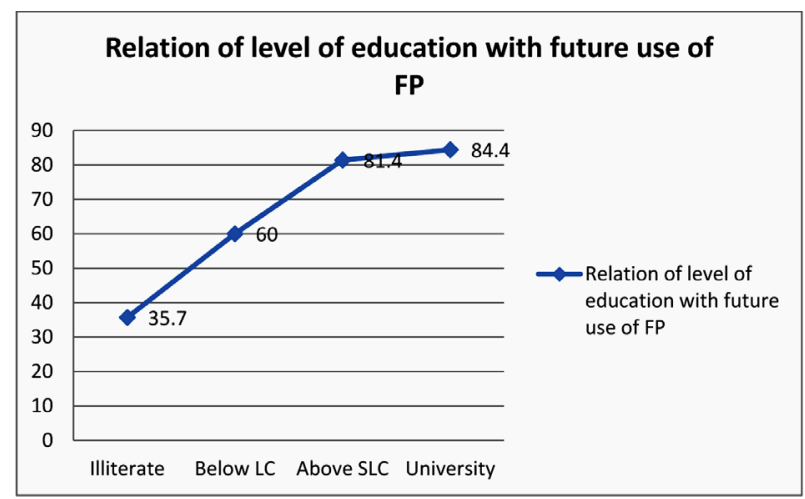

Figure 5. Comparison of mother's education level with future use of family planning methods.

were condom $84 \%$ followed by OCPs $82 \%$, Depot provera $71.50 \%$, IUCDs $56.80 \%$ and female sterilization $55.80 \%$ respectively in decreasing order.

Family planning awareness and future use by education level:

The level of women's education had a significant impact on future use and non-use of postpartum contraception. Highly educated women were more willing to use contraceptives in this period as compared to uneducated women. This may be due to the fact that highly educated women are more likely to appreciate the advantages of fewer better educated children. ${ }^{11}$ In this study, we observed women whose education level above SLC were aware of the contraceptives (93.30\%) and those of master's level were willing to use them for future as well (84.40\%). Another study done by Shah also reported women's education to be a significant variable, as the use increased from $43 \%$ in primary educated women to $70 \%$ in secondary and higher educated women. ${ }^{12}$

The findings of the present study suggest that rural parts and uneducated women are still lagging behind in regard to postpartum contraceptive use. It was observed that knowledge and awareness does not always lead to use of contraceptives among the couples. Family planning counseling needs to be universally and effectively included into routine antenatal activities and also during their postpartum period. Efforts should be made to educate the 
public about safety modern, long term, reversible methods of contraception among both the

\section{Source of information of family planning services:}

In our study, out of 400, 223 (55.70\%) women obtained information from media (TV, radio, magazines, newspapers), 179 (35.05\%) from health personnel, 94 (23.50\%) from friends, relatives or neighbors and $19(4.80 \%)$ from private sectors.

In contrast to this study, one of the Korean study revealed the main source of information to be health center or relatives and neighbors. ${ }^{13}$ Another study done in Manipur, India also reported that the main source of knowledge was from friends (44\%) followed by mass media which is only $22 \% .{ }^{14}$ Mass media exposure also plays a very important role in women's decision about whether to adopt contraceptives or not. Hence, more emphasis should be given to media in order to disseminate information among the general public.

\section{Attitude of Women regarding contraceptive use:}

In this study, out of 400 participants, 274 (68.50\%) women had positive attitude regarding contraceptive use. Similarly, $36(9 \%)$ had no response or neutral attitude (not willing to talk or discuss about the family planning methods) and 90 (22.5\%) had negative attitude (opposed to use contraceptive methods) in this study. The reason behind their negative attitude towards contraceptive was because of the side effects of depot provera like irregular menstrual period, amenorrhoea, abdominal bloatedness, weight gain and headache.

\section{Awareness and past use of family planning methods:}

Present study showed $60.50 \%$ use of family planning methods in the past and $39.50 \%$ of the women had never used any methods, in contrast to the high level of awareness i.e. $90.80 \%$. This finding is similar with the study done in Nigeria, where an awareness rate is $92.50 \%$, only $25.70 \%$ had used one form or the other form of contraception and $66.40 \%$ were willing to use the contraceptives in the future. ${ }^{15}$

In present study, it was found that only $0.50 \%$ used IUCDs which is quite low in comparison with the study done in Reba, India where $16.90 \%$ women used IUCDs. ${ }^{16}$ The low use of IUCDs in this study was fear of complications like displacement, perforations and various other wrong myths regarding IUCDs. Hence, there is a need to educate women on knowledge of the various contraceptive methods, myths and realities about contraception in order to change the trend. This shows that improved counseling is needed about possible side effects and correct use of particular contraceptive.

\section{CONCLUSION}

In this study, the contraceptive awareness and knowledge among the postpartum women was high but their usage was low. Hence, efforts should be made to educate the public about the safety, proper usage and convenience of modern, long-term, reversible methods of contraception. Health care personnel should also counsel the clients for adopting the contraceptives according to their need.

\section{ACKNOWLEDGEMENT}

I would like to thank Prof. Rachana Saha for her support and Department of Gynae/Obstetric department for their immense help in conducting this study.

\section{REFERENCES}

1. Karlsen S, Say L, Souza JP, Houe CJ, Calles DL, Gulmezoglu AM, et al. The relationship between maternal education and mortality among giving birth in health care institutions: Analysis of the cross sectional WHO Global Survey on Maternal and perinatal Health. BMC Public Health 2011; 11:606.

2. Sedgh et al. Women with an unmet need for contraception in developing countries and their reasons for not using a method. Occasional report, New York: Guttmacher Institute no.37, 2007.

3. Adamson P. Women: maternal mortality. Commentary. In: The progress of nations. New York: UNICEFF, 1996:2-9.

4. Maternal Mortality: Helping women off the road to death. Report of the inter-regional meetings on the prevention of maternal mortality. WHO chronicle, 1986; 40(5):175-183.

5. Ross JA and Frankenberg E. Findings from Two Decades of Family Planning Research, New York: Population Council, 1993.
6. Ministry of Health and population (Nepal). Nepal Demographic and Survey 2011. Kathmandu.Nepal: Ministry of Health and Population, New ERA and ICF International Inc. Calverton, Maryland, USA; 2012.

7. Ministry of Health and Population, New Era, ICF Macro, USAID. Nepal Demographic and Health Survey 2011. Kathmandu Ministry of Health and Population; 2012.

8. Kaushal SK, S C Saxena, V K Srivastava, S C Gupta, S Nigam. KAP study on contraceptive methods in Kanpur district of UP. Indian Journal of Community Health, vol21: no.2, vol22 no.1 July 2009-June 2010.

9. Dabral S, S L Malik. Demographic study of Gujjars of Delhi: IV KAP of family planning. J Hum Ecol 2004; 16(4):231-7.

10. Oye-Adeniran BA, Adewole IF, Odeyemi KA, Ekanem EE. Contraceptive prevalence among young Women in Nigeria. J. Obstet Gynecol. 2005; 25(2):182-5.

11. Kanoja JK, Nirbharvane NC. Dynamics of contraceptive practice among urban Indian women. Nat'I Med J India. 1996; 9:109-12. 
12. Shah NM. Past and current contraceptive use in Pakistan. Study in FP 1979; 10:164-73.

13. Planned Parenthood Federation of Korea PPFK Yonsei University. Center for Population and Family Planning. Benchmark survey report on community based distribution of contraceptives in Korea. 1976; 51-64.

14. John Mao. Knowledge, attitude and practice of family planning: A study of Tezu village, Manipur (India). The Internet J of Biol Anthropol. 2007; 1.
15. Okezie C A, Ogbe AO \& Okezie C R.Socio-economic determinants of contraceptive use among rural women in Ikwuano Local Government Area of Abia state, Nigeria. International NGO Journal. 2010; 5:747 Allagoa D.O. Knowledge attitude and practice of contraception among antenatal patients. The Nigerian Health Journal. 2011 julysept;11(3):89-92.

16. Vishwakarma K, Yadav K, Bhargava M. A study of awareness and attitude of postnatal and post abortal women towards family planning methods and their use, at rural tertiary centre. $J$ of Evolution of Medical and Dental Sciences 2014 May 26;3(21):5849-58. 